\section{Retrosigmoid approach for glycerin rhizotomy in the treatment of trigeminal neuralgia without overt arterial compression: updated case series}

TO THE READERSHIP: An error appeared in the article by Kim et al. (Kim TY, Jackson CM, Xia Y, et al: Retrosigmoid approach for glycerin rhizotomy in the treatment of trigeminal neuralgia without overt arterial compression: updated case series. J Neurosurg [epub ahead of print March 8, 2019; DOI: 10.3171/2018.12.JNS182572]).

Due to a production error, the legend for Fig. 1 was not updated in the online ahead-of-print article prior to its publication. The figure appears here with the correct legend.

We apologize to the authors for this oversight. The article has been corrected online as of March 29, 2019.

\author{
Gillian Shasby \\ Director of Publications \\ Journal of Neurosurgery Publishing Group, Charlottesville, VA
}

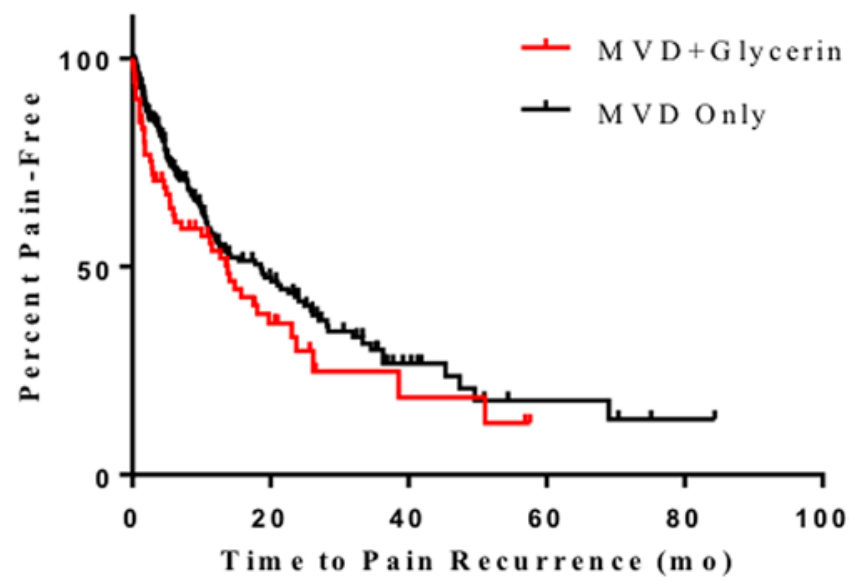

FIG. 1. Kaplan-Meier pain recurrence rate in patients who experienced pain recurrence after MVD only and MVD+glycerin injection treatment. No statistical significance was found $(p=0.08)$. Figure is available in color online only.

CORRESPONDING ARTICLE See pp 1227-1233.

INCLUDE WHEN CITING

Published online March 29, 2019; DOI: 10.3171/2019.3.JNS182572a.

CAANS 2020, except where prohibited by US copyright law 